\title{
Acting together; ensemble as a democratic process in art and life
}

(Neelands, Jonothan (2009) 'Acting together: ensemble as a democratic process in art and life', Research in Drama Education: The Journal of Applied Theatre and Performance, 14:2,173 - 189)

Professor Jonothan Neelands is a National Teaching Fellow and Chair of drama and theatre education in the Institute of Education at the University of Warwick, England. He is also Deputy Director (Pedagogy) of CAPITAL (creativity and performance in teaching and learning), a centre of excellence in partnership between the Royal Shakespeare Company (RSC) and Warwick. He teaches on the MA in Drama and Theatre Education and enjoys working as a practitioner in a diverse range of educational settings. Recent research projects have included the RSC, the Birmingham Royal Ballet and the National Association of Youth Theatre. His research interests include the politics of cultural and education policy-making, teaching in urban settings, the sociology of educational disadvantage and the articulation of a pro-social pedagogy of dramatic practice.

j.neelands@warwick.ac.uk

Institute of Education

University of Warwick

Coventry CV4 7AL 


\title{
Acting together; ensemble as a democratic process in art and life
}

\author{
Abstract: \\ Traditionally drama in schools has been seen either as a learning medium with a wide \\ range of curricular uses or as a subject in its own right. This paper argues that the real \\ importance of drama in schools is contained in the processes of social and artistic \\ engagement and experiencing of drama rather than in its outcomes. Learning to act as a \\ social and artistic ensemble and experiencing how to work and live together based on \\ the model of the drama ensemble are fore grounded in this paper. In the ensemble \\ based model of drama the effects of drama go beyond the boundaries of the subject and \\ the classroom and have the ambition of impacting on young people's quality of life and \\ learning in the wider community. \\ The paper contrasts the pro-social emphasis in the ensemble model of drama with the \\ pro-technical and limited range of learning in subject based approaches which \\ foreground technical knowledge of periods, plays, styles and genres. The ensemble \\ based approach is positioned in the wider context of professional theatre understandings \\ of ensemble artistry as well as in the context of revolutionary shifts from the pro- \\ technical to the pro-social in educational and cultural policy making in England. Using \\ ideas drawn from John McGrath and Cornelius Castoriadis, the paper claims that the \\ democratic ensemble approach to drama provides young people with a model of \\ democratic living and a means of continually re-imagining and questioning the idea of \\ how best to live as interdependent human beings.
}

Keywords: Ensemble, process, social imagination, democracy and theatre, citizenship, community, political theatre. 


\title{
Acting together; ensemble as a democratic process in art and life
}

\begin{abstract}
Outside the doors, we've never had more cause to realise the grave importance of our interdependence as humans and yet we seem ever more incapable of acting on that realisation with the same urgency that we all still give to the pursuit of self interest. Theatre does have a very important role because it is such a quintessentially collaborative art form. That gift of collaboration to the audience and (potentially, yes) to the outside world - is a very precious one. (Michael Boyd, Artistic Director Royal Shakespeare Company - RSC ${ }^{1}$ )
\end{abstract}

\section{From pro-technical to pro-social experiences of drama education}

Two schools, in England 2008. The first is buried in the scarred landscape of the Nottinghamshire coal fields. Long abandoned. The industry is dead; there are no jobs, fewer prospects. The town is bleak and shuttered. Not much to do, not much to hope for. Twenty years ago the local secondary school on the hill was a dangerous place for young teachers like me. Rough, often aggressive, echoing the 'tough' of the older mining community. The school had an impressively bad reputation both for poor results and poor everything else. Returning, fearfully, to give a workshop to 15 year olds based on Shaun Tan's The Arrival I cannot believe or understand the transformation. The school is now a Specialist Performing Arts College. The corridors are filled with quiet talking, no one pushes or jostles, children greet each other without expletives, gentle boys strum guitars in corners. In the workshop boys and boys, boys and girls, girls and girls focus for an hour or more on how the hand of a mother comes to be placed on the hand of a father on a closed suitcase on the eve of migration. This is serious work. No blushes, no pushing away, no hiding behind barricades of indifference. Boys touch boys, girls touch boys in every case with the intent of discovering the meaning in the action and what it says of others who seek a better world because their own is boarded up and empty. The most recent school inspection report reads:

In the many lessons observed inspectors saw good relationships between students and adults, and students co-operating with one another productively... They move around the college sensibly and respond positively when given demanding work to do. Although a significant minority of parents expressed concerns about behaviour, the inspectors saw little that was untoward and these incidents were invariably the result of teaching that did not sufficiently engage students in their studies. (OfSTED ${ }^{2}$ Report 11/07)

The second is enveloped by the urban decay of Leicester. An old landscape peopled with new communities of migrants. The school has faced challenges in insisting on its secularity and commitment to the democratic principles of mutual respect and equality of

\footnotetext{
${ }^{1}$ Taken from the transcripts of the Ensemble Theatre Conference $23^{\text {rd }}$ November 2004 organised by Equity UK and Directors Guild

${ }^{2}$ Office for Standards in Education (OfSTED), is the English schools inspection agency with powers to judge a school's performance against national standards
} 
opportunities for all including the right of all its children to be involved in drama and dance. In 2004, OfSTED judged the school to be failing. These new arrivals were failing against national standards of numeracy and literacy, despite the fact that $98 \%$ of them were struggling to acquire hybridity in a new language, a new culture, and new hopes. The drama in the school was particularly criticised by OfSTED because of the poor standards of acting and the lack of scripts. The real work of the school made invisible in their technical and faceless measurements of 'excellence'.

Now in 2008, in a class on King Lear I nearly miss a group of girls huddled together, Hindu and Muslim, purposefully poring over an image of Lear; touching, laughing. Looking closely at each other as they listen. These children model a future. They have struggled, out of necessity, to find a common culture in the classroom, in the playground, in the local streets. And in this school, drama has, for many years, been part of this struggling towards a common culture, which might transcend the historical mistrust and fear of the other which still haunts their homelands in the Indian sub-continent. This is drama being used as a process of healing and being together (Schechner 1994). Out of necessity, the school has given added value to nurturing what Friere called 'vital knowledge':

The kind of knowledge that becomes solidarity, becomes a 'being with'. In that context, the future is seen, not as inexorable, but as something that is constructed by people engaged together in life, in history. It's the knowledge that sees history as possibility and not as already determined the world is not finished. It is always in the process of becoming. (Friere 1998, p. 72)

In this school Drama has provided a powerful integrative force for bringing unfamiliar knowledge into knowing engagement. For helping students to make contextual and authentic connections between the abstractions of an English National Curriculum and the heartbeat of their own lived experience as new arrivals with different ontological and epistemological traditions in their travel sacks. But it has also been a process of ensemble making. A way of modelling how through collective artistry, negotiation, contracting of behaviour and skilful leading, the ensemble in the classroom might become a model of how to live in the world; a model of 'being with'. In 2008 there is a second OfSTED inspection:

The school has developed a particularly strong drama programme that has been used very effectively to raise the pupils' self-esteem, improve behaviour and raise the quality of pupils' work in English. This has resulted in a significant drop in exclusions and recorded racist incidents. Pupils are confident, behave well and get on well with one another. (OfSTED Inspection Report 02/08)

There are two points to be made here. The first is how in schools like these that adopt drama as a pro-social ensemble-based process for building community and a common culture (Neelands 2009) young people are beginning to model the conditions for a future society based in the necessity of learning how to live with the grave importance of our interdependence as humans. In both cases, children and young people have been led to imagine and look for new ways of living together rather than against each other; to find solidarity in their common disadvantage; to create new models of pluralist community. They are responding to Michael Boyd's question: 
Can an ensemble... act in some sense as a ...better version of the real world on an achievable scale which celebrates the virtues of collaboration? $?^{3}$

The lessons learnt in both schools have not been confined to a particular subject or to the classroom. They have reached out beyond the school, beyond the narrowing limits of subject boundaries. The quality of work in English is now set against the significant human advances credited to drama in the second school report.

The second point is to note the shift in the ideology of inspection of schools in England away from a foreground of pro-technical measurements of literacy and numeracy scores towards a more pro-social assessment of how the school is also working towards meeting the personal, social, emotional, spiritual and political needs of young people facing an uncertain future. This shifting towards the pro-social includes a decentring of the narrow compass of subjects as the 'natural' way of organising, limiting, delivering and assessing knowledge (knowing) in schools in England. There is not the space here to list all of the social and economic reasons that have necessitated this profound shift in UK educational policy. But it is witnessed in the new political emphasis on well-being for children from the Every Child Matters legislation and agenda ${ }^{4}$; in the national obsession with creativity in schools, communities and business; in the move to a Bigger Picture for the New Secondary Curriculum. One consequence has been a growing awareness that schooling rather than being an end in itself, measured by success in subjects, is part of a life long process of learning in and out of school that needs to address life-wide rather than narrowly academic needs.

The QCA's ${ }^{5}$ Bigger Picture of the English secondary curriculum has three principle and over-arching aims which are that children should become - Successful learners; Confident individuals and Responsible citizens. In the Bigger Picture, subjects are still important in so far as they contribute to these objectives, but the measurement of academic success in individual subjects is mediated with other holistic and human achievements. The Bigger Picture's pro-social objectives include: understand their own and others' cultures and traditions, within the context of British heritage, and have a strong sense of their own place in the world; challenge injustice, are committed to human rights and strive to live peaceably with others; take account of the needs of present and future generations in the choices they make.

These are not the kinds of objectives that can be delivered in isolated subject silos, nor are they intended to be. If they are achievable at all it will only be through the integration and blurring of the boundaries between personal and social learning and academic learning; learning between subjects as much as within them.

\footnotetext{
${ }^{3}$ Ensemble Theatre Conference 2004

${ }^{4}$ The Children Act 2004 provides the legal underpinning for the transformation of children's services as set out in the Every Child Matters: Change for Children programme. The five common aims are: stay healthy; stay safe; enjoy and achieve; make a positive contribution; achieve economic well being.

${ }^{5} \mathrm{QCA}$ - the Qualifications and Curriculum Authority is the regulatory body in England for the National Curriculum and all qualifications. The Bigger Picture can be viewed at: www.qca.org.uk/qca 5856\#2630253
} 
There are pro-market as well as pro-social reasons for this turn towards life-long, lifewide and integrative pedagogic aspirations. In an influential Demos ${ }^{6}$ publication entitled the Creative Age, the authors argue, from a pro-market perspective, that:

While qualifications are still integral to personal success, it is no longer enough for students to show that they are capable of passing public examinations. To thrive in an economy defined by the innovative application of knowledge, we must be able to do more than absorb and feedback information. Learners and workers must draw on their entire spectrum of learning experiences and apply what they have learned in new and creative ways. A central challenge for the education system is therefore to find ways of embedding learning in a range of meaningful contexts, where students can use their knowledge and skills creatively to make an impact on the world around them. (Seltzer and Bentley 2000, p.11)

The idea that working/acting together to integrate knowledge from the entire spectrum of learning experiences in meaningful contexts is an economic necessity as well as a social one is of course an important shaping influence on the new curriculum. But the promarket need for a bigger picture of the curriculum also resonates with Maxine Greene's pro-social conception of the need to see things big rather than seeing small (Greene 1995):

Seeing schooling small is pre-occupied with test scores, 'time on task', management procedures, ethnic and racial percentages and accountability measures, while it screens out the faces and gestures of individuals, of actual living persons. (p.11)

At this level of seeing small, human knowledge is reified and fixed into the facts, figures and other surface features of a traditional subject or collection code in which learners compete with each other to acquire knowledge as 'private property' rather than as a social resource. (Bernstein 1973 p. 142)

In Bernstein's theory of educational codes, the key concept of the collection code is 'discipline', learning to work within a received frame, learning and accepting which questions are appropriate, accepting that knowledge is hierarchically ordered over time. Evaluation is sequenced to reflect the temporal and artificial stratification of knowledge. Success at one level allows progression to the next, the levels are objectively determined. Knowledge under the collection code also socialises children into knowledge frames which discourage connections with everyday realities. This disassociation of school learning from the real world and the pursuit of subject knowledge rather than personally meaningful knowledge is increasingly recognized as failing to meet the full range of needs of young people. In the introduction to_Authentic Achievement, Newmann et al. (1995) preface the findings of large scale empirical research into effective pedagogy with these words:

The kind of achievement required for students to earn school credits, grades and high scores on tests is often considered trivial, contrived, and meaningless by

${ }^{6}$ DEMOS is a left of centre government think tank which has significantly influenced New Labour's education, social and cultural policy making 
both students and adults, and the absence of meaning breeds low student engagement in school work. Meaningless schoolwork is a consequence of a number of factors but especially curriculum that emphasises superficial exposure to hundreds of isolated pieces of knowledge. The term authentic achievement thus stands for intellectual accomplishments that are worthwhile, significant and meaningful, such as those undertaken by successful adults: scientists, musicians, entrepreneurs, politicians. (p.26)

\section{From subject to subjects}

Traditionally, of course, drama-in-education (process drama), with its emphasis on decentring the power of the teacher, negotiated learning and encouraging deeper contextual explorations of the bigger questions of life, has tended to flourish in the context of a bigger picture curriculum The pedagogy of process drama sits more comfortably with and is paradigmatic of Bernstein's integrated code of boundary-less knowledge, connecting classroom learning to the world beyond, establishing relevance and authenticity in learning and asking complex questions about the world which includes but is not limited to school. In the integrated code:

The particulars of each subject are likely to have reduced significance. This will focus attention upon the deep structure of each subject, rather than on its surface structure.... this is likely to affect the orientation of the pedagogy, which will be less concerned to emphasise the need to acquire states of knowledge, but will be more concerned to emphasise how knowledge is created...is likely to emphasise various ways of knowing in the pedagogical relationships...(1973, p.242)

But there is a newer tradition of drama in schools, in England at least, which often refers to itself as 'drama as a subject in its own right' and which seeks to establish a boundaried and limited subject domain or territory for drama within a collection code curriculum framework (Kempe and Ashwell 2001, ACE 2003).

Drama has its own history and body of work, much of which has a unique and important place in our cultural life. In common with all subjects, it requires specific skills, knowledge and understanding which are progressively taught and assessed through and across the key stages. (ACE 2002, p.1)

This new tradition has been particularly dominant in English schools in the last decade and has tended to shift the emphasis in drama education towards foregrounding the protechnical acquisition and measurement of 'subject knowledge' and 'products' in drama and back grounding the pro-social objectives and integrative and experiential epistemology of the process drama tradition.

So that in a popular text for drama teachers like Progression in Secondary Drama (Kempe and Ashwell 2001) for instance, the authors list the following pro-social claims for the place of drama in the curriculum: promotes self-expression; builds selfconfidence; enhances creativity; encourages communication as being fine and laudable But the authors argue that firstly these aims are for all teachers rather than for drama teachers and that secondly because they cannot be assessed and measured there is no logic in seeing such aims as being the preserve of the drama curriculum (page 1).

Whilst agreeing with the subject paradigm's assertion that the development of personal and social skills is not the preserve of the drama curriculum it is the responsibility of all teachers and also agreeing that young people's drama should include learning the craft 
of theatre and something of its many histories, I want to argue in the remainder of this paper that my opening examples suggest that drama does have a unique and important contribution to make to children's social and political development in particular and that this is at the heart not only of school drama but drama in a democratic society. I also want to argue that the separation of the social from the artistic in the dominant subject paradigm in England unpicks the unique weave of drama as a living practice beyond schools. That drama in schools should be both artistically and socially progressive for young people.

The danger can be that in seeking to circumscribe and proscribe the boundaries and contents of drama as a collection code subject, it becomes detached from drama as a living practice and from the kinds of knowing and learning which come from the direct participatory engagement with drama as an experiential learning process (Kolb 1984). It also becomes detached from the bigger picture questions raised in related areas of the curriculum such as the humanities and English. It marginalises the kinds of social learning that characterise the qualities of drama in the two examples with which this paper opened.

\section{Theatre apart from our lives or a part of our lives?}

The disassociation of the arts from other living practices, and of artistic knowledge from other human knowledge, which is a characteristic of the subject drama position, is a familiar strategy for those who claim, in the Kantian tradition, that the arts are autonomous and transcendent from the muck and murk of everyday life. This distinction between artistic and social practices and development is seen by Bourdieu, Ranciére and others as a means of neutralising the power of the arts to illuminate the social and inequitable conditions of the world and also to naturalise the tastes and preferences of dominant social and economic groups (Bourdieu, 1984, 2003 Ranciére, 2004).

In outlining the functions of theatre in an authentic democracy ${ }^{7}$, the late John McGrath suggested, in contrast, that theatre has a role to play in: giving a voice to the excluded; giving a voice to the minority; demanding the right to speak publically, to criticize without fear; questioning the borders of freedom.

...theatre, of all the arts, surely works at the interface between the creative and the political, calling together audiences of citizens to contemplate their society or its ways. ..the theatre can only renew itself for audiences and for theatre-makers if it is part of the times it lives in. Pure art there has never been, least of all 'pure' theatre. (McGrath 2000 p.137/138)

He went on to argue that theatre teaches through its paedia or pedagogy of being relevant to the world experiences and deepest concerns of its participants; accurate in terms of its truth for participants and its cultural accessibility as a birthright for all rather than for the few. In this model the technical craft of theatre communication serves rather than replaces a communal and public search for 'troubled truths'. The content is fore grounded, but can only be materialised through the technical crafts and forms of theatre.

\footnotetext{
${ }^{7}$ McGrath borrows the term 'authentic democracy' from Castoriadis who uses it to distinguish the ideals of direct and participatory forms of democracy from the corrupted actuals of 'representative democracy' (Castoriadis, 1983)
} 
But this model is still an abstraction. It talks about 'theatre' without making reference to what can be learnt from our public and social experiencing of theatre; from acting together socially and artistically. In this respect there is the possibility to argue for a model of ensemble based drama education which seeks common ground around the idea that it is the paedia of the participatory experience of being together in drama and how children and young people are changed by that which is important rather than the form of the drama work itself. It might be in a process drama experience or in a musical theatre production process, or it might be, as in my two examples, part of a continuing and broader cultural agenda. It's the quality of the social and democratic 'being with' in the paedia of theatre that makes the distinctive difference to what is learnt in drama.

If we compare industry and art: in industry the value is in the result; you produce a thing and they pay you for what you have produced; in art the value is not in the result but rather in the process. (Lev Dodin, artistic director, Maly Theatre of St Petersburg ${ }^{8}$ )

In my opening examples it was the ongoing experience of being together in drama, which was contributing to change rather than a particular lesson or production. The effects of being together in drama went beyond a drama box. They were part of a public and participatory process of changing cultures and attitudes. In this sense, young people in both schools were learning how to act together in both artistic and social domains, so that their learning about how to act together in the drama classroom was also shaping their social actions as a community beyond the drama class and also, possibly, beyond school.

This is the point being made in the OfSTED report on the second school. It is also the foundation of a new publication for the UK government's Innovation Unit ${ }^{9}$ by the influential public policy theorist Charles Leadbeater (2008). In What's Next? 21 ideas for $21^{\text {st }}$ Century Learning Leadbeater makes the same claim that:

The route to a more socially just, inclusive education system, one which engages, motivates and rewards all, is through a more personalised approach to learning. Learning with, rather than learning from, should be the motto of the system going forward: learning through relationships not systems. (p.79)

This claim that it is the process of 'being with' in drama that is paramount echoes a communitarian tradition in political theory with its origins in Aristotle. James Tully for instance, argues that it is the process of political struggle itself rather than the outcomes that have the potential to develop a second order identity as an active and civically engaged citizen (2000). Homi Bhabha uses the example of the women who joined the struggle to protect the livelihood and existence of their communities during the 19841985 Miners Strike in the UK to make the same point. This was the same catastrophic struggle that shaped the community of the first school example at the head of this paper. Bhabha's point is that these women did not lose a strike. They were changed by it. The

\footnotetext{
${ }^{8}$ Ensemble Theatre Conference 2004

${ }^{9}$ www.innovation-unit.co.u\#905D60
} 
process of active, civic engagement in the belief that the world is changeable was the lasting legacy of the struggle not its immediate outcome. (Bhabha 1994 P27-28).

\section{Andres gar polis; better to be in an ensemble than a gang}

A democratic, libertarian, egalitarian company presenting plays of great diversity could express an ideal of a world I want to live in. (Trevor Nunn; director ${ }^{10}$ )

Working together in the social and egalitarian conditions of ensemble based drama, young people have the opportunity to struggle with the demands of becoming a self-managing, self-governing, self-regulating social group who co-create artistically and socially and to be begin to model these ideals of the Athenian polis (autonomous, autodikos, autoteles) beyond their classrooms The ensemble serves as a bridging metaphor between the social and the artistic; between the informal uses of classroom drama and professional theatre. The idea of the ensemble has the potential of reconciling the tensions between the social and the artistic. It opens dialogue around a common theme between subject based paradigms of drama and those that are more concerned with responding to the personal and social needs of young people. It also unifies drama education models of all kinds with the world of professional ensemble theatre. There is a renewed awareness in the professional sector that ensemble building is a pre-requisite for theatre making of the highest quality. Geoffrey Streatfeild, one of the members of the Royal Shakespeare Company's Histories ensemble (2006-2008), describes working in the ensemble in this way:

Our ever growing trust enables us to experiment, improvise and rework on the floor with an astonishing freedom and confidence. This ensemble is a secure environment without ever being a comfort zone. All of us are continually challenging ourselves and being inspired by those around us to reach new levels in all aspects of our work. (Cited in RSC Histories Cycle Programme Notes 2007)

This is an affirmation that at the heart of theatre, whatever the context, is the desire to create a secure environment without ever being a comfort zone. It gives witness to the power of the ensemble way of working to push young people towards new levels of collective social and artistic excellence. Critically, Streatfeild celebrates the powerful creative synergy which can be released through collective artistry; through solidarity of being and purpose.

As a participant observer in the Histories Cycle rehearsal room in 2007, I was struck by the commonalities between the professional and educational ethea of the ensemble. On a day, which included both the RSC rehearsals and watching a skilled drama educator in a classroom, I made these notes:

The principles of the ensemble, in both the educational and professional spheres require the uncrowning and distribution of the power of the director/teacher, a mutual respect amongst the players, a shared commitment to truth, a sense of

\footnotetext{
${ }^{10}$ Ensemble Theatre Conference 2004
} 
the intrinsic value of theatre making, a shared absorption in the artistic process of dialogic and social meaning making. ${ }^{11}$

There are resonances in these principles with what Cornelius Castrodiadis (1983) calls the 'germ' of democracy with its origins in $5^{\text {th }}$ Century Greece and Athens in particular.

Greece is the social-historical locus where democracy and philosophy are created; thus of course it is our own origin. In so far as the meaning and potency of this creation are not exhausted...Greece is for us a germ neither a 'model', nor one specimen amongst others, but a 'germ'. (p. 272)

In Greece we have the first instance of a community explicitly deliberating about its laws and changing those laws based on the principles of: the ekklesia

Isonomia; equality in respect of the law

Isegoria; the right to speak

Isopsephia; equal representation

Parrhesia; moral obligation to speak your mind

Autonomia; right to self determination

These principles strike a chord with the idea of the social and ethical contract, which underpins the educational and professional models of the ensemble (Neelands 1984, Nicholson 2002) as well as the idea of ensemble as a model of how to live together in the world. The demands of living and learning together in drama require, in any case, a form of constitutional learning based on the negotiation and continual re-negotiation of the 'laws' in the learning group. Students cannot be coerced into role-playing or other forms of artistic acting for instance, they must enter into it willingly and this presupposes a pedagogy of choice based consciously or unconsciously on the principles of the ekklesia and the temporary 'uncrowning' and distribution of the power of the teacher in favour of a more democratic and demanding autonomy. It is common practice, in schools in England at least, for teachers to negotiate a contract or constitution for learning and living together in drama with their students and this is often prominently and publically displayed in the drama space and open to continual re-negotiation. Here is an actor/teacher in Australia describing this process $^{12}$ :

I began by asking them for definitions of 'ensemble' what it might mean and how it might work and was pleased by how many responses I had. I asked the students to suggest a 'code of practice' that would help make the classes as productive as possible - for everyone - They had a number of suggestions and insisted we frame our code as an acronym - PERL.

Participation; willingness to participate, to take risks and be bold

11 Author's unpublished field notes April $24^{\text {th }} 2007$

${ }^{12}$ Provided by a colloquium participant from her own direct experience with a class Melbourne 2008 


\title{
Ensemble; working enthusiastically as part of an ensemble
}

\author{
Respect; for each other's work
}

\section{Listening; to instructions and to each other}

Michael Boyd's question is whether an ensemble can act in some sense as a ...better version of the real world on an achievable scale which celebrates the virtues of collaboration. The claim for the importance of the experience of ensemble in drama education is based on this idea of 'achievable scale'; that at the level of the classroom and the teachers and young people who use it, it ought to be possible to offer some working and active idea, at least, of what a democratic civic life might look like. From a different perspective the social and interactive demands of living and learning as a social but also artistic ensemble are also likely to encourage the development of 'social intelligence' because as Boyd reminds us, theatre is a quintessentially collaborative art form. For instance the following are seen as indicators of higher level social intelligence (Orlik, P. 1978, Sternberg, Conway, Ketron \& Bernstein 1981): accept others for what they are; admit mistakes; display interest in the world at large; have social conscience; think before speaking and doing; understand people's thoughts, feelings, and intentions well; are good at taking the perspective of other people; are open to new experiences, ideas, and values.

\section{Change the world; it needs it}

Castroiadis (1983) argues that theatre was indispensible to the political ideals of the Athenian polis. Castoriadis demonstrates that there was no concept of the fixity of government or laws, or of the civic world as being anything other than temporally imagined, unfinished and becoming in Ancient Athens. The Athenians had no word for 'state' for instance - andres gar polis (the city is the people) in Thucydides's formulation. The transformations of the stage were a living reminder that the laws and rules and institutions of public life were only 'social imaginaries', which could be transformed trough the collective exercise of the social imagination of the polis. The kratos (power) of the polis was that its people determined their own laws and changed them when necessary - they were not 'givens' imposed by divine or aristocratic right. The mindset of the Athenian invention of Tragedy was 'universality and impartiality' (ibid. p 284). Tragedy stressed the commonality of living and the importance of seeing the world through the eyes of others. Aeschylus's Persians and Euripides Trojan Women both present Athens's enemies as having just cause and equal claim to the truth. Just as in the ensemble, the ekklesia held the collective and direct power to socially imagine and re-imagine the most effective and equitable means of self-governance, and this social reimagining of how best to live together was a constant and participatory process.

But theatre in the form of tragedy also served the political purpose of revealing to the polis its limitations as well as its possibilities. To show the world as changeable but also to show through the concept of hubris the limits of personal and collective action when these overstep or ignore the principles of democratic life. Ensemble based drama holds the potential for both of these possibilities. Combining the living experience of the democratic polis on a smaller scale, which Pericles described as the creation of human beings, living in beauty, living in wisdom, loving the common good, with the theatrical means of both showing what needs to be changed and imagining and deliberating how it might be changed (Boal 1987). 
The idea that the arts can be personally transformative has become a common theme in New Labour's cultural, social and educational policymaking in the UK (Neelands, Freakley and Lindsay 2006). Most recently, the government announced plans to give every child access to five hours of cultural activity every week. In the prospectus for bids for ten pilot schemes the claim is that:

Culture enriches lives. Participation in cultural activities can have a significant impact on young people's development.... As well as being valuable and enjoyable in its own right, participation in cultural activities also gives young people the chance to develop important life skills such as creativity, confidence, self-discipline, effective communication and the ability to work in teams (Unlocking Talent DCMS/DCSF 2008)

But there is in the idea of the ensemble the possibility of social as well as personal transformations.

One of the great services theatre can perform for the people of any country or region or town or village is to be the instrument of authentic democracy, or at the very least to push the community as near to authentic democracy as has yet been achieved. (McGrath 2004, p.133)

Of course there are problems in drawing these analogies between collections of artists and learners struggling to find equitable and effective means for producing art and the lessons of ancient Athens. The polis was exclusive to men of means and gradually in both the theatre and the politics there was a move towards representative politics rather than authentic, or direct, politics (Boal 1987). Direct participatory and deliberative action by all, was replaced by representative action by a few in both the theatre and the civic theatre of political life. And so it has remained. In so called Western democracies the few represent the many in the political sphere just as the few represent the many in the dominant theatre tradition, which makes the mass of the audience into passive nonactors, and the few on the stage to act on our behalf and in our place. The idea that we are all social actors with the possibility of being our own artistic actors in the direction of our realities and our dramas will need to be reclaimed.

The next project, then, is to look beyond the effects of single dramas and beyond the subject and school and to ask whether over time ensemble based theatre can offer a model of a fully participatory, rather than representational, democratic community offering a fully participatory, rather than representational, theatre. A better version of the real world on an achievable scale.

\section{References:}

Arts Council England (2001) Drama in Schools $2^{\text {nd }}$ Edition London; ACE

Bernstein, B. (1973) Class, Codes and Control Vol. 1, Paladin; London

Boal, A. (1976). Theatre of the Oppressed. London; Pluto Press

Bhabha, H. (1994) The Location of Culture London; Routledge 
Bourdieu, P. (1984) (Nice, R. trans) Distinction; A Social Critique of the Judgement of Taste Cambridge, Mass; Harvard University Press;

Bourdieu, P. (1993) The Field of Cultural Production: Essays on Art and Literature Cambridge; Polity Press

Castoriadis, C. (1983) The Greek Polis and the Creation of Democracy (1983) in Curtis , D. (Ed) (1997) The Castoriadis Reader Oxford; Blackwell

Freire, P. (1998) Pedagogy of Freedom New York; Rowman and Littlefield;

Greene, M. (1995) Releasing the Imagination New York; Jossey-Bass;

Holden, J. (2008) Culture and Learning; towards a new agenda London; DEMOS

Kempe, A \& Ashwell, M. (2001) Progression in Secondary Drama London; Heinemann.

Kolb, D. (1984) Experiential learning : experience as the source of learning and development London : Prentice-Hall

Leadbeater, C. 2008 What's next? 21 ideas for $21^{\text {st }}$ Century Learning London; Innovation Unit

McGrath, J. (2002) Theatre and Democracy, in New Theatre Quarterly (2002), 18: 99100 Cambridge University Press

Neelands, J. (1984) Making Sense of Drama London; Heinemann

Neelands, J, Freakley, V. and Lindsay, G.(2006) THINGS CAN ONLY GET BETTER; A study of social-market interventions in the shaping of the field of cultural production in International journal of Cultural Policy Vol. 12 No 1.

Neelands, J. (2009) Getting off the Subject: English, Drama, Media and the Commonwealth of Culture, in Manuel, J. Andersen, M. and Cater, D. (2008) Revisioning English Education: Imagination, Innovation, Creativity Sydney; University of Sydney Press

Newman, F. (and associates) (1995) Authentic Achievement Jossey-Bass; New York

Nicholson, H. (2002) The Politics of Trust: drama education and the ethic of care in RIDE Vol. 7 No. 1

Orlik, P. (1978). Social intelligence. In K.J. Klauer (Ed.), Handbook of pedagogical diagnosis Dusseldorf: Schwann.

Ranciére, J. (2004) The Distribution of the Sensible in Rancierre, J. (2004) The Politics of Aesthetics London; Continuum

Royal Shakespeare Company (2007) Programme notes for the Histories Cycle Stratford Upon Avon; RSC

Seltzer, K. and Bentley, T. (2002) The Creative Age: Knowledge and skills for the new economy London; DEMOS 
Sternberg, R.J. Conway, B.E., Ketron, J.L., \& Bernstein, M. (1981) People's conceptions of intelligence. Journal of Personality \& Social Psychology, 41, (37-55)

Tan, S. (2007) The Arrival London; Hodders

Tully, J. (2000) Struggles over Recognition and Distribution Constellations, 7/4 (469-482) 